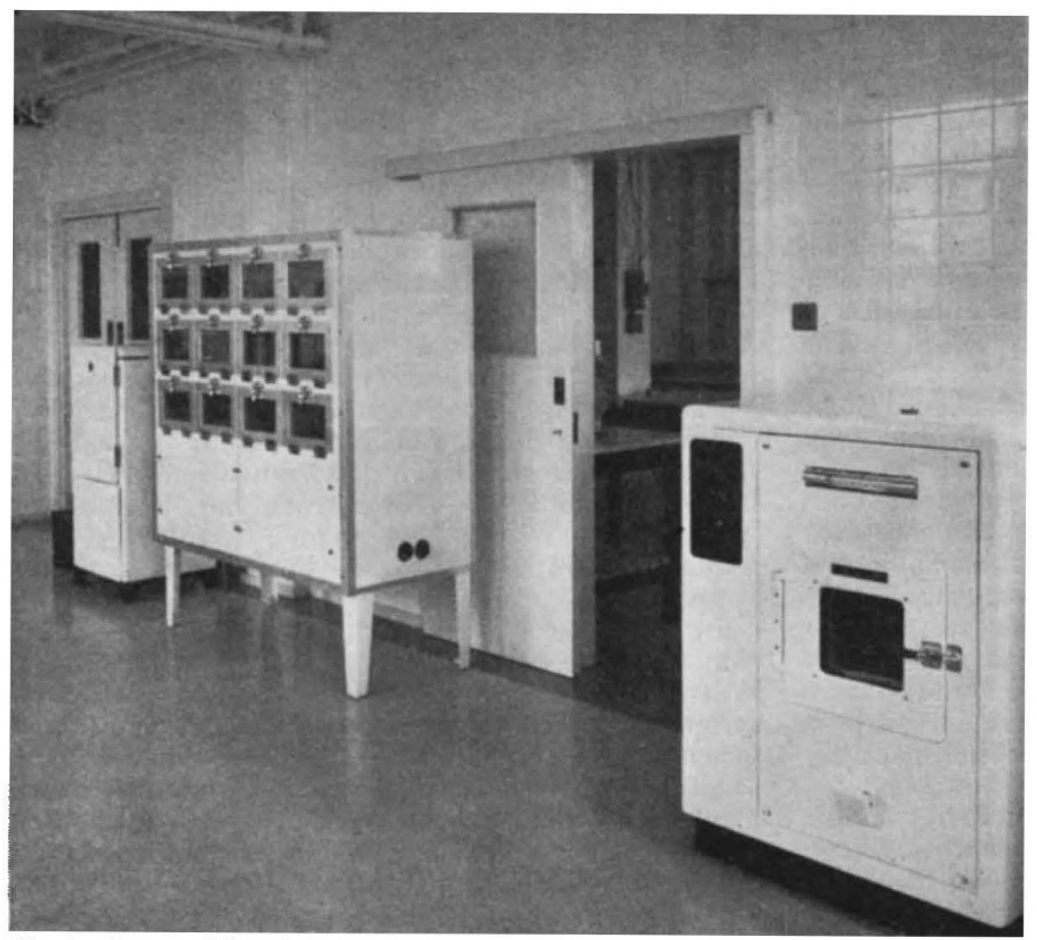

Fig. 1. Corner of Bread Bakery, Cereals Research Station, St. Albans, leading to the Constant Temperature Laboratory

wheat grain, with the distribution of the B vitamins and vitamin $\mathrm{E}$, varietal differences in wheat and how they affect milling and baking properties, the chemistry of the wheat proteins, nutritional studies on wheat and flour as shown by experiments on the rat, experiments on dental caries, the chemistry of cereal lipids, certain aspects of flour milling technology, including the air classification of flour, rheological studies on dough, problems specific to oats and oat products and the avoidance of rodent contamination of cereals on the farm.

To mark the occasion, a book was prepared, entitled "The Research Association of British Flour Millers, 1923-1960", which includes abstracts of the 376 scientific and technical papers published by the Association. The abstracts are grouped in three categories-basic, agricultural and technological. In the introduction, the president writes : "Speaking for my Council, I would like to stress that in our opinion the main function of the Research Association is to carry out basal research. I would add, too, that in our experience the practical results that have followed amply justify this policy. That does not mean that some routine and ad hoc work is not.necessary. It is, if only to keep the staff in touch and in sympathy with millers' day to day problems. Nor has research on flowr milling as such been neglected. I have only to refer to our recent work on the separation from ordinary flour, by air classifieation, of fractions rich or poor in protein. This may be a major development in the history of flour milling. I believe therefore that the Research Association has for some years struck about the right balance between basal and applied research".
T. MoraN

\title{
NATURE AND EXPLOITATION OF CROP PLANT RESISTANCE TO DISEASE
}

\begin{abstract}
A SYMPOSIUM on the nature and exploitation of crop plant resistance to disease, organized jointly by the Association of Applied Biologists (president, Dr. R. V. Harris) and the British Mycological Society (president, Mr. E. C. Large), was held at the London School of Hygiene and Tropical Medicine during January 8-9.

The first day's proceedings were devoted to studies on the host plant, and, in a general introduction, Dr. G. D. H. Bell said how much he appreciated the initiative of the sponsors in arranging this important symposium. The efficient exploitation of disease resistance required the collaboration of both the pathologist and the plant breeder. Obviously the breeder tended to be more concerned with the host than with the pathogen, and although it was accepted as sound breeding policy to handle disease resistance in much the same way as other breeding characters, the genetics of the pathogen had to be considered as well as that of the host. Disease resistance was, of course, expressed in different ways, while various systems of genetic control were known. Major gene resistance in the host had been exploited
\end{abstract}

extensively, but that based on minor genes was undoubtedly safer in many circumstances.

Dr. R. C. F. Macer (Plant Breeding Institute, Cambridge), who considered developments in breeding disease-resistant cereals, suggested that the problems were for the first time being dealt with adequately in Great Britain. The synthesis of wheat lines with genes for resistance to Puccinia glumarum, Erysiphe graminis and Cercosporella herpotrichoides were given as examples of progress being made; in some cases it had been found desirable to use sources of resistance found in allied species and genera. The closed-flowering character of barley was described as an escape mechanism giving protection from all races of Ustilago nuda.

Some of the difficulties in breeding for resistance to certain diseases in vegetable crops were outlined by Dr. J. C. Haigh (Wellesbourne), who described the present position in lettuce with regard to mosaic disease, downy mildew (Bremia lactucae) and mould (Botrytis cinerea). He also referred to the difficulties of using Lycopersicum pimpinellifolium and $L$. hirsutum as sources of resistance to Cladosporium 
fulvum and Didymella lycopersici in breeding outdoor tomatoes.

Dr. R. L. Knight, Miss E. Keep and Mr. J. B. Briggs (East Malling) gave an interesting account of the possible control of a disease by breeding for resistance to its vector. Amphophora rubi is the aphid vector of several raspberry viruses, and specific genes have been found in the hosts which give resistance to particular strains of the aphid. The authors considered that there was a good chance of the breeding work being able to keep ahead of the aphid for some time to come.

Dr. D. S. Kirkham and Dr. A. E. Flood (Fast Malling) discussed apple and pear scab, and they described a resistance mechanism based on biochemical differences. Characteristic phenolic substances were found to be present in the two-host, species and quantitative differences in these have been demonstrated between resistant and susceptible varieties. Using the sporulation of the fungi (Venturia inaequalis and $V$. pirina) as a measure of biological activity, chlorogenic acid was found to have an inhibitory effect. These fungi have a narrow host specialization, and resistance to them can apparently be conferred by one or more major genes.

Another type of biochemical resistance, but in this case acting outside the plant through root exudates, was described by Dr. E. W. Buxton (Rothamsted) in relation to studies with pea wilt resistance. Pea varieties differ in their susceptibility to individual races of Fusarium oxysporum f. pisi and resistance appears to be associated with inhibition of growth by the root exudates. The exact nature of the exudate is unknown, but it probably took effect in the rhizosphere, acting either directly upon the parasite, or indirectly by first affecting the associated microorganisms.

Prof. S. C. Harland, introducing the discussion, said that such joint meetings between scientists of different disciplines were long overdue. He believed that the fundamental information necessary in breeding for disease resistance was a knowledge of the breoding system and the genetic architecture of both the host and the pathogen. He felt that it was necessary, on a long-term basis, to recognize the fact that single major gene resistance was less stable than that based on a number of minor genes, and further consideration should be given to the exploitation of types of resistance known variously as field resistance and adult plant resistance. Prof. Harland wondered whether the time had not come to reconsider the use of induced mutations as a practical method of increasing the variability of the host plants.

The papers on the second day were introduced by Prof. D. Lewis, who briefly summarized the ways in which fungal variability may occur: by mutation, by genetic recombination in sexual reproduction, by segregation of nuclei from heterocaryons and by the parasexual phenomenon. Variation in pathogenicity was now known to occur so rapidly that it often seemed capable of overcoming resistance available to the plant breeder, particularly where reliance was placed upon major gene resistance, which exerted vigorous selection upon the pathogens. Prof. Lewis then contrasted the ability of fungi to break down the resistance of plants with their apparent failure to overcome the toxicity of fungicides.

The paper by Mr. A. C. Hastie (Rothamsted) on "Variation in Verticillium albo-atrum isolated from Hops" described experiments, using nutritionally deficient mutants, to determine the mechanisms responsible for variation in this imperfect fungus. Mixed inoculum of isolates differing in nutritional deficiencies, when grown on an unaugmented agar medium, resulted in heterocaryon formation. It may now be inferred that a system similar to parasexuality may give rise to novel progeny. This work is at present being extended to include an investigation of the possibility of these mechanisms also being responsible for variation in pathogenicity.

Dr. R. D. Tinline of the Canada Department of Agriculture, at present working at Rothamsted, reported in his paper "Pathogenic and Cultural Variation in Cochliobolus sativus" that variation in culture of this fungus was brought about by mutation, by heterokaryosis and by hybridization. He was, however, unable to demonstrate the existence of 'parasitic races' of this fungus; virulent isolates tended to be highly pathogenic on all thirty-six wheat. varieties used in the tests.

In her paper "Interaction, or Genetic Recombination, between Potato Viruses $Y$ and $C^{\prime \prime}$, Dr. Marion Watson (Rothamsted) suggested that variation in the symptoms produced by inoculation of closely related virus strains may indicate the formation of mixed isolates of viruses. Experiments using potato viruses $Y$ and $C$, which are serologically related, and are strains of the same virus, showed that viruses with attributes of both $Y$ and $C$ could be obtained from lesions produced by inoculating a mixture of viruses $Y$ and $C$. Such new strains were obtained only when the viruses inoculated were related strains, and also possibly when the multiplication took place within the same host cells.

Physiological specialization in Puccinia glumarum and Phytophthora infestans was discussed by $\mathrm{Dr}$. D. A. Doling (National Institute of Agricultural Botany, Cambridge) with particular reference to race surveys. Such surveys supply information upon the number of races present and their relative frequency and distribution in particular areas. The value of the information obtained, however, depends very much on the organization of the actual collections. The identification of races presents problems of selection of suitable differential host varieties and of methods of inoculation and incubation. The most satisfactory host varieties are those containing known combinations of resistance genes.

Dr. C. C. V. Batts (London) gave a historical account of the distribution of physiological races of Puccinia glumarum in Britain since 1946. During this period the number of races identified each year has declined, but new biotypes of two races were now important and were associated with the wheat varieties being grown. The system of international trials being earried out in Western Europe were an extension of the race survey technique discussed by Dr. Doling and were useful in determining the distribution of physiological races over a larger area and also in suggesting suitable resistant varieties. The race position in Ustilago tritici was discussed in relation to the reactions of differential varieties. The type of reaction produced is apparently dependent upon the location of the mycelium within the embryo.

The problem of resistance to potato blight (Phytophthora infestans) was discussed by Dr. W. Black (Scottish Plant Breeding Station). Solanum demissum was a valuable source of resistance due to the hypersensitivity reaction, but from 1932 onwards the fungus has produced new races (now numbering at least 20) which could attack seedlings containing the $R$ genes 
from $S$. demissum. However, in addition to the $R$ gene resistance, 'field resistance' was also known which is at present effective against all races. The approach now being made is to combine $R$ genes with the 'field resistance', which is inherited polygenically, so that varieties could be produced with a high level of resistance to some, and 'field resistance' to all, races.

The final discussion was opened by Prof. C. T. Ingold who, after surveying the various methods used for identifying physiological races of pathogenic fungi, turned to the more genetical aspects of problems. He considered that the importance of the parasexual cycle was not fully appreciated and in the future needed further investigation on a broad front.

This symposium drew together geneticists, virologists, pathologists and plant breeders who were involved in improving the productivity of crop plants.
It is to be hoped that this will be the first of a series of such joint meetings in which scientists of different disciplines can consider together topics of common interest. These discussions were, however, particu. larly opportune as the rapid advances made in micro. bial genetics, the information collected as a result of expanded breeding programmes and the experience gained in handling resistant varieties in the past decade, need careful integration if the undoubted benefits of disease resistance are to be fully exploited. Although few fundamentally new ideas emerged from the papers it was clear that the complexities of incorporating stable forms of resistance in commercially acceptable varieties were fully realized. There was nevertheless a feeling that, at least for some crops, the future promised an improved standard of disease resistance based largely upon mechanisms controlled by minor gene systems.

R. C. F. Macer

\section{THE DEVELOPMENT OF SCIENCE IN SOUTH-EAST ASIA}

A REGIONAL meeting, to discuss problems of organizing scientific research in South-East Asian countries, was held at Bandung, Indonesia, during December 9-12, 1959. It was organized jointly by the Unesco South-East Asia Science Co-operation Office and the Indonesian Council of Sciences, and was attended by senior representatives of the national research organizations or other appropriate bodies of the following countries: Australia, Hong Kong, India, Indonesia, Japan, Malaya, Philippines, Thailand, Republic of Vietnam, and New Zealand. The meeting was inaugurated with an opening address by the Minister of Education, Instruction and Culture of Indonesia, Prof. Prijono, in the National Planning Board building in Bandung, which had been the scens of the historic Afro-Asian Conference in 1955. Prof. Prijono emphasized that the development of science and technology has not always been accompanied by moral progress, and appealed to the delegates to apply their learning for universal development, based on the common needs of man. The president of the Council of Sciences of Indonesia, Prof. Sarwono Prawirohardjo, was elected ehairman of the meeting.

The business sessions of the meeting were held in the impressive headquarters of the National Science Foundation of Indonesia. From the outset of the discussions, stress was laid on informality. It was believed that a frank exchange of views would be more beneficial than formal debates on a number of fixed points, and this indeed proved to be the case. The stages of scientific development of the countries attending the meeting varied considerably-some had long-established government scientific research organizations, whereas others had only recently set up such bodies. After a survey of the main features of government research organization in each country, delegates discussed some of the major organizational problems which they faced. One of these was to determine the optimum balance between fundamental and applied research which they should undertake. It was recognized that developing countries have many urgent problems requiring immediate practical solution, and that it is usually easier to persuade governments to provide funds for research which has a definite practical objective. The traditional role of the universities in research is also to undertake fundamental work. Nevertheless, the meeting felt most strongly that it is essential for the health of national research organizations that they should be free to undertake fundamental work as they think desirable, and to approach any applied problem as basically as is necessary.

Another problem was concerned with the proper responsibilities of a national research organization. These, of course, vary with the country concerned. In some countries of the region the national scientific organizations are operating bodies, maintaining their own laboratories and employing their own staff; in others they are co-ordinating bodies advising their governments on development of policy and distribution of funds. The meeting stressed that in either case it is essential that the national scientific organization should have the maximum possible degree of autonomy of operation and in administering the funds provided for it by its government.

The relative functions of universities and national research organizations were also discussed. It is essential that university research should be effective in training students in the practice and philosophy of research, and for this reason governments should be prepared to provide funds for university research without any conditions as to the projects on which they should be employed.

One particularly interesting discussion covered the conditions for attracting and holding good scientists in the service of national research organizations. This is a vital matter, particularly for countries with national organizations in the early stages of development. The meeting placed great weight on the need for providing as liberal employment conditions as possible. Scientists look for autonomy of the organization, and freedom from political interference and rigid departmental control; the provision of suitable salaries and other conditions of service such as adequate equipment and trained assistance ; freedom. of publication; liberal travel grants and study leave, ete. It was also agreed that it is most important that the management of scientific organizations should be in the hands of scientists.

As was inevitable at such a meeting, the provision of finance and resources for research eame in for 